\title{
Urban heritage walks in a rapidly changing city: tensions between preservation and development on the Gold Coast, Australia
}

\author{
Zelmarie Cantillon ${ }^{\mathrm{a} *}$ \\ ${ }^{a}$ Griffith Centre for Social and Cultural Research, Griffith University, Gold Coast, \\ Australia
}

*Griffith Centre for Social and Cultural Research, Griffith University, Gold Coast Campus, Parklands Drive, Southport, QLD, 4222, Australia. Email:

z.cantillon@griffith.edu.au

ORCID ID: https://orcid.org/0000-0001-9869-217X

This article examines the emergence of urban heritage walks on the Gold Coast, Australia. As a popular beachside mass tourism destination, the Gold Coast has a longstanding reputation for rapid development and for lacking historical and cultural depth. In this context, heritage walks present an opportunity to reorient the city's identity and to stage a sense of heritage in the urban environment. Focusing on a case study of the Gold Coast's Southport Heritage Walk (SHW), this article aims to analyse the discursive, material and political dimensions of urban heritage walks, and how practices of heritage unfold in places marked by rapidly changing urban landscapes and resident populations. Drawing on observational fieldwork, as well as interviews with key individuals involved in designing the walks, the article discusses the dominant narratives of history and urban identity enshrined in the SHW, and how these discourses are encountered and interpreted within the context of the contemporary materialities of lived space. Although the SHW aims to highlight the city as a place with a rich history and heritage, the walk's missing interpretive markers and scarce remnants of built heritage instead emphasise the city's ongoing tensions between development and preservation.

Keywords: heritage walks; heritage trails; Gold Coast; urban identity; heritage interpretation 


\section{Introduction}

Heritage walks represent the connection and interpretation of particular sites of historical and cultural significance to form a cohesive, 'themed journey' (MacLeod, 2017, p. 423) through space. Such trails are increasingly ubiquitous in cities around the world, offering themselves as low-cost, low-maintenance attractions for tourists and residents alike. This article examines the emergence of urban heritage walks on the Gold Coast, Australia, a city with a reputation for rapid development. Long known as Australia's premier beachside mass tourism destination, the Gold Coast is often stereotyped as lacking historical and cultural depth (see Cantillon, 2019). Recently, however, the city council has been making concerted attempts to reposition its identity, framing it as a sophisticated, world-class city rather than an overgrown resort. In policy documents, a turn towards supporting cultural activities and heritage initiatives (including heritage tourism) has been framed as integral to this urban reimaging project.

This article draws on observational fieldwork on each of the Gold Coast's seven self-guided heritage walks and trails, focusing particularly on the case study of the Southport Heritage Walk, located in the suburb in which the author lives and works. To gain further insight into how and why the heritage walks were developed, and how they are maintained, brief, semi-structured interviews were undertaken with three individuals who were involved with the development of the heritage walks.

Using the Gold Coast as a case study, the primary aim of this article is to analyse the discursive, material and political dimensions of urban heritage walks. To meet this aim, the article has three key objectives: first, to consider how practices of heritage unfold in places marked by rapidly changing urban landscapes and resident populations; second, to examine which sites, people and stories are represented in the Southport Heritage Walk and what kinds of narratives of urban identity the walk expresses; and 
third, to discuss how these discourses may be encountered and interpreted in situ, within the context of contemporary materialities of lived space. Through this analysis, the article finds that instead of evoking a sense of place characterised by a rich history, the walk's missing interpretative markers and disappearing buildings instead highlight ongoing tensions between development and preservation in the city. Before delving into this analysis, the article outlines the context for this research through an overview of the scholarly literature on heritage trails and the study's theoretical and methodological frameworks, followed by some background information on the Gold Coast and its heritage walks.

\section{Conceptualising heritage walks, trails and routes}

Heritage trails vary significantly in length, location and scope, from short, city-centre walks, to extended hikes, scenic drives and international trade routes. Although not a new phenomenon, heritage trails have only recently received greater attention in scholarly literature, as signified by the emergence over the last several years of two special issues of journals ('Heritage Trails and Tourism' in Journal of Heritage Tourism, 2017; 'Exploring Interpretive Trails' in Journal of Community Archaeology \& Heritage, 2015), a monograph on tourism trails (Timothy \& Boyd, 2015), and a number of journal articles. This body of literature analyses the particularities of different heritage trails, as well as the diverse forms, functions, effects and experiences of trails more broadly.

Timothy and Boyd (2015) distinguish between 'organic' and 'purposive' routes, the former referring to those established for pilgrimages, migration, trade or railways, and the latter being those that are intentionally constructed - often linking together sites thematically - for contemporary use. These purposive routes are diverse in focus, with scholarly literature examining heritage trails based on, for example, famous historical 
figures (see Fagence, 2017), remembrance of war (see Miles, 2017), or marginalised groups (see Sesma, 2015). Although the literature tends to focus on heritage trails as forms of cultural tourism geared towards outsiders (see MacLeod, 2017; Timothy \& Boyd, 2015; Al-hagla, 2010; Hayes \& MacLeod, 2007), they may also specifically target the local communities in which they are situated, or envisage their users as tourists and residents alike (see Barber, 2018).

Heritage walks can further be differentiated between 'government-generated, market-oriented, and community-based' initiatives (Barber, 2018, p. 1). This typology reflects the variances that can be found in the aims, content, funding, promotion and overall formalisation or sophistication of purposive trails (Barber, 2018; see also Hayes \& MacLeod, 2008). Depending on these factors, heritage walks may be guided, selfguided or a combination of both, and may feature different modes of interpretation including directional markers, informational panels or commemorative plaques, digital or printed brochures, audio recordings, and mobile apps (Markwell et al., 2004; Hayes \& MacLeod, 2007; Timothy \& Boyd, 2015; MacLeod, 2017).

The functions and purposes of heritage walks also vary widely. Timothy and Boyd (2015, pp. 18-19) outline four key purposes of cultural heritage trails: promoting preservation and conservation; fostering economic development; enhancing a city's image or a sense of place; and achieving political aims. That is, firstly, the creation of heritage trails can involve or impel the preservation of tangible and intangible heritage, educate the general public about (particular versions of) history, and raise awareness and interest in conservation projects (Markwell et al., 2004; Al-hagla, 2010; Saiyed, Basalingappa, \& Sinha, 2017). Secondly, these attractions can provide opportunities for economic development through their promotion as tourism experiences and by 
attracting visitors to businesses and other heritage institutions (e.g. museums) along the route (see Prideaux, 2002).

Thirdly, heritage trails can improve the image of a place and act as a placemaking strategy (see Markwell et al., 2004). Place-making can be described as the process through which meanings are ascribed to social spaces, including specific sites, neighbourhoods or whole cities. As tools for storytelling, heritage trails construct a particular narrative of identity - 'a unifying frame through which the diversity of place can be viewed' (MacLeod, 2017, 424). This emphasis on local distinctiveness can also potentially promote senses of wellbeing, local pride and place attachment for the communities in which they are situated (Kenworthy Teather \& Chow, 2003; Markwell et al., 2004; Hayes \& MacLeod, 2008). As Dobson (2011, p. 109) notes, these benefits are most likely to manifest when heritage walks invite 'multiple interpretations' of place and history. In the words of Markwell et al. (2004, p. 458), 'place-making and local cultural heritage awareness projects ... help provide reference points for the development and expression of local identities and for framing a sense of belonging'.

Finally, heritage trails are inherently 'political projects' (Taylor, 2015, p. 108), and can thus function as 'instruments to exercise power and persuasion' (Timothy and Boyd, 2015, p. 19). Heritage interpretation is not a 'value-free or politically neutral process of information transmission' (Markwell et al., 2004, p. 459). As Smith (2006, p. 3) explains, sites and artefacts are 'not inherently valuable, nor do they carry a freight of innate meaning'; rather, sites and artefacts are continuously inscribed with significance and meaning through social, cultural and political processes (see also Ashworth \& Graham, 2005). Designing and implementing a heritage walk constitutes one such mode of meaning-making. Through processes of selection, organisation and interpretation, heritage walks indicate which sites are deemed 'worthy' of preservation, visitation and 
remembrance. As such, the walks can privilege particular perspectives over others, reflecting dominant historical narratives or an 'authorised heritage discourse', or, conversely, manifesting as subaltern projects (Smith, 2006) that present and legitimise alternative, marginalised or untold histories (Taylor, 2015; MacLeod, 2017; Barber, 2018).

This article is concerned with self-guided, government-generated, purposive urban heritage walks on the Gold Coast, Australia. The analysis in this article is underpinned by a critical heritage studies approach, which accounts for "the larger issues that bear upon and extend outwards from heritage' (Winter 2013, p. 533), including 'regional and global transformations' (p. 542). In other words, the article aims to discuss broader social and political shifts through its examination of heritage. Specifically, the article considers how heritage unfolds in a rapidly changing city shaped by pro-development urban policies and a significant tourism economy.

As heritage walks are inherently spatial phenomena, this article is also underpinned by approaches to analysing space/place drawn from cultural geography and urban cultural studies. Following the work of Henri Lefebvre (1991 [1974]), Edward W. Soja (1996) and Doreen Massey (2005), this article understands urban space as produced through a multiplicity of intersecting elements. In Soja's (1996, pp. 5-6) terms, space is constituted by the 'real' (materiality and the built environment), the 'imagined' (representations and discourses) and the 'real-and-imagined' (lived experiences and spatial practices) (see also Lefebvre 1991). Therefore, this article examines the discursive qualities of heritage walks, their material existence within the urban environment, and the lived experience of undertaking them.

In conceptualising the role of place-making, this article acknowledges that space/place is relational and 'always in the process of being made' (Massey, 2005, p. 9; 
see also Friedmann, 2010; Pierce, Martin, \& Murphy, 2010). Place-making occurs through a range of activities, including macro-level, policy-led strategies focused on city branding and urban renewal as well as more micro-level, informal engagements such as those of people engaging in everyday socio-spatial practices. Aligned with the critical heritage studies approach, this understanding of place-making takes into account the multiple local and global forces that shape spatiality and the heritagisation of cityspace. The Gold Coast's heritage walks were implemented as strategies for placemaking and community renewal, political projects aimed at making a particular kind of place - reorienting the city's image and future trajectories. However, as discussed below, the materiality of lived space can disrupt such strategies and reveal different meanings altogether.

\section{Methodology}

This article is based on a qualitative inquiry informed by a range of ethnographic methods (Silverman, 2013; Flick, 2009; Gray, 2003), including semi-structured interviews, observational fieldwork and visual methods (photography). Data was primarily collected through observational fieldwork (Angrosino, 2007) framed through analytical autoethnographic techniques (Chang, 2008). That is, rather than approaching the field as a 'detached' observer, the author set out to undertake the heritage walks in ways that reflexively accounted for her embodied experiences, situated knowledges and subjective positions as simultaneously researcher and resident (see Gray, 2003; Haraway, 1988). The observational work sought to glean insights related to the key objectives of the research: to examine how heritage initiatives play out in a rapidly changing city; to analyse the content of the walks and what histories and identities they represent; and to interrogate the relations between discursive interpretive tools, the materiality of urban space and the lived experience of doing the walk. Walks were 
undertaken over the course of six weeks, always during the daytime and accompanied by a friend or relative. Observations were recorded via written field notes on a smartphone; digital audio recordings of verbal reflections; and photographs aimed at capturing the walk's interpretive tools in the context of their urban environment.

To complement the observational fieldwork, the author also undertook three semi-structured interviews (Flick, 2009) with individuals involved in the development and implementation of the Gold Coast's heritage walks. Interviews were digitally audio recorded and ranged from 20-40 minutes in length, focussing on how and why the heritage walks were developed and how they are maintained. In this article, interviewees are referred to as Respondents 1,2 and 3. As only a small number of individuals worked on creating the walks, their specific roles and contributions are not disclosed so as to protect their anonymity. The use of verbatim quotes has been limited to ensure participants are not identifiable based on their turns of phrase or specific experiences.

Audio recordings of interviews and observations were transcribed and analysed along with the author's written fieldnotes and photographs to identify key themes and issues. Although the dataset includes data from all of the Gold Coast's heritage walks, this article adopts a case study approach (Feagin, Orum, \& Sjoberg, 1991) to focus specifically on what the Southport Heritage Walk may reveal about the discursive, material and political dimensions of urban heritage walks.

\section{Case study: Reorienting urban identity on the Gold Coast, Australia}

With a population of about 570,000, the Gold Coast is Australia's sixth largest city and its largest non-capital city. Located in the south-east of the state of Queensland, the Gold Coast has long been known as one of Australia's premier resorts, famous for its 
natural assets - long stretches of beach, good surf, subtropical weather and a lush hinterland - as well as its manufactured attractions - family-friendly theme parks, a strong nightlife scene, and an extensive range of hotels and tourism amenities. The city is an example of tourism urbanisation (Mullins, 1992) in that its most spectacular development since European colonisation has been driven by tourism and leisure industries rather than manufacturing, trade or government administration, as with more conventional urban formations.

The traditional custodians of the area known today as the Gold Coast are the Yugambeh peoples, specifically the Kombumerri clan. Having inhabited the area for tens of thousands of years, they developed complex practices and knowledge regarding the use and management of the area's natural resources. Following European colonisation, economic activities in the area were initially centred on agriculture and timber-getting, but by the late 1800 s the tourism industry was starting to develop. From the 1930 s to 1950 s, the growth of rail networks, commercial flights and increasing car ownership sustained the Gold Coast as a popular destination for interstate visitors. Subsequent decades saw the rapid development of high-rises, theme parks, shopping malls, a casino and other tourism facilities. By the 1980s, the Gold Coast solidified itself as an international mass tourism destination. With roughly 160,000 visitors in the early 1960 s, these numbers grew to 1.6 million in the early 1980 s and to 4 million in the early 2000s (Prideaux, 2004). Resident populations increased alongside the growth of tourism, from roughly 34,000 in 1961 to 105,000 in 1981 and 424,000 in 2001 (State of Queensland, 2009). Today, tourism and related industries - encompassing hospitality, retail, construction and real estate - continue to be key to the economy of the city, which attracts upwards of 5 million overnight visitors per year, or a total of 13 million including regional daytrippers (Tourism and Events Queensland, 2018). 
The Gold Coast's identity is, therefore, strongly associated with 'sun, sand and sex' mass tourism. Imagined and represented as a space for escapism, fantasy and hedonism, the Gold Coast's own tourism narratives have positioned it as disembedded from mundane life, and from its historical, social and cultural contexts (see also Cantillon, 2019; Wise, 2006). Some of the most pervasive stereotypes about the city are that it is a 'cultural desert' (see [removed for peer review]; Smith, 2018; Stephens, 2013) and a 'dehistoricized space' (Wise, 2006, p. 181). This is further compounded by the city's reputation for rapid urban development. Cranes are perpetual features of the Gold Coast skyline, as buildings are regularly demolished and replaced with taller, more contemporary structures. As the author has written elsewhere (Cantillon, 2019), there is also a sense among locals that the city tends to privilege the interests of developers, investors and tourists over the needs and desires of residents. Under these circumstances, buildings have little chance to reach an age at which they may be considered worthy of heritagisation, and calls on behalf of residents to preserve certain sites have had little impact. The Gold Coast is thus associated more strongly with impermanence and change than preservation or continuity, concepts typically understood as core to heritage practices.

It is unsurprising, then, that the city is not known for its heritage attractions. In recent years, however, the local government has been placing increasing emphasis on cultural and heritage initiatives. This move has been particularly pronounced in the lead up to and aftermath of the 2018 Commonwealth Games, which the Gold Coast hosted. Policy documents make clear that the Gold Coast is committed to reorienting its urban identity, positioning itself as a vibrant, sophisticated, 'mature', 'world-class city' (Council of the City of Gold Coast, 2018) rather than just an overdeveloped, superficial 
resort. The Gold Coast's City Plan highlights the potential role that heritage tourism and other heritage projects may play in shaping its image:

A strong focus on cultural heritage and urban design excellence ... forms a vital element of any world-class city. The Gold Coast values its cultural heritage: Our places, buildings, landscapes, artefacts, memorabilia or stories told by our pioneers. Conserving important cultural heritage buildings and places will maintain our rich diversity and unique Gold Coast character. [H]eritage tourism will in turn support our City's economy. (Council of the City of Gold Coast, 2018)

Similarly, the current Culture Strategy document emphasises the need to more deliberately preserve and celebrate local cultural heritage (specifically Indigenous heritage and 'post-1945 heritage') in order to enhance community wellbeing, foster economic growth (e.g. through diversifying the city's tourism offerings) and 'promote the Gold Coast as a place with a distinct and enviable cultural identity and lifestyle' (City of Gold Coast, 2014, p. 12).

At present, there are several Council-run initiatives that aim to document and preserve the city's heritage, although many of these have not yet been integrated into or foregrounded in official tourism promotions. Heritage initiatives include the Gold Coast Heritage Register, which protects both natural and built heritage, and the Local Studies Library, a publicly accessible archive of local history which preserves materials such as photographs, maps, local history books/dossiers, newspapers, oral histories, Council minutes, birth, death and marriage registers, and other documents. Most other heritage institutions in the city are community-based efforts - for example, Surf World, which is a museum dedicated to surfing and beach culture; the Gold Coast Hinterland Heritage Museum, which exhibits structures and memorabilia from the early period of European colonisation; and the Yugambeh Museum Language and Heritage Research, which aims to collect, preserve and display materials relating to the Yugambeh language region. 
Exhibitions related to heritage are also held occasionally at local libraries, and the Gold Coast City Art Gallery makes a substantial contribution to the curation and display of local heritage, holding exhibits focused on the city's urban development, tourism economy and beach culture. For instance, in 2013 the Art Gallery held 'Learning from Surfers Paradise: A Rephotography Project, 1973 to 2013', which featured side-by-side comparisons of photographer John Gollings' captures of the same sites across the city, providing visual documentation of the Gold Coast's rapidly transforming built landscape. In addition to these initiatives, the Gold Coast has also developed the series of self-guided heritage walks which are the focus of this article.

\section{The Gold Coast's heritage walks}

The Gold Coast currently has seven heritage walks: Labrador Heritage Walk (est. 2007); Southport Heritage Walk (est. 2009); Coolangatta Heritage Walk (est. 2013); Mudgeeraba Heritage Walk (est. 2015); Nerang Heritage Walk (est. 2017); the Kokoda Memorial Walk (est. 2008, located in Broadbeach); and the Commonwealth Walkway (est. 2017, located in Southport, Main Beach, Surfers Paradise and Bundall). With the exception of the Kokoda Memorial Walk - which seeks to commemorate battles fought between Australian and Japanese forces on the Kokoda Track, Papua New Guinea during World War II - and the Commonwealth Walkway - which stretches across four suburbs and aims to represent Gold Coast history more broadly - each of the other walks focuses on the history of a particular suburb. These walks vary from approximately three to ten kilometres in length, taking anywhere from one to four hours to complete depending on the route taken (most of the walks offer two or three routes) and time spent reading plaques, taking photographs, navigating, resting or exploring beyond the trail. Each is a government-generated walk, designed and overseen by the Council of City of Gold Coast (in particular, the Local Studies Library and the Office of 
City Architect). In the case of the Southport and Labrador walks, the impetus to create the walks came from funding from the Queensland Government's Community Renewal program and 10,000 Steps initiative. Stops on the walks encompass a number of locallyor state-listed heritage places as well as places of interest that are not formally protected.

Although all of the walks have been developed by the local council, their interpretive tools are not uniform and instead attend to the specificities of each suburb. For example, Labrador has purposely-designed interpretive panels at each stop, while Southport has a series of interpretive and directional markers in pathways (see Figure 1), along with three informational totem poles (see Figure 2). The walks in Coolangatta, Nerang and Mudgeeraba do not feature any infrastructure specifically implemented to facilitate the heritage walks, instead relying on existing commemorative plaques and other signage. Additionally, while all walks have an accompanying brochure with map - available either digitally or in printed form at local library branches - these differ considerably in length, detail, appearance and content.

[Insert Figure 1 here]

[Insert Figure 2 here]

Respondents indicated that the walks were aimed at the general public, including both residents and tourists. However, while the Gold Coast's history and identity are closely intertwined with its tourism economy, most of the walks are located outside of the city's key tourism hubs (Surfers Paradise and Broadbeach), reducing the likelihood that tourists may encounter them. Further, despite the City Plan highlighting the potential for heritage tourism on the Gold Coast, the walks are not currently advertised 
on the city's official tourism website, nor are they mentioned in tourism-related policy documents. In the case of the Southport Heritage Walk (discussed at length below), this may be due to the fact that it was not designed specifically as a tourism attraction, but rather was initiated to promote liveability and community renewal: 'the ... project will increase residents' knowledge of their local community, provide an opportunity for community engagement, increase physical activity and provide a platform for local history to be incorporated into the local school curriculum' (Queensland Government, 2008, p. 30). Heritage is thereby used as a 'resource[] for the present' (Ashworth \& Graham 2005, 24) to 'encourage people to explore environment' (Respondent 2), strengthen a 'sense of place' and promote 'local pride' through celebrating elements of local specificity (Respondent 2 and Respondent 3 ). In this context, place-making is not merely altruistic, but also political, functioning as a strategy of 'urban re-imaging' (Markwell et al., 2004, p. 458) through staging the urban environment as a heritage product. In the section that follows, the Southport Heritage Walk (SHW) is used as a case study to explore some of the political dimensions of how heritage walks are constructed, how they are experienced in situ, and how they capture particular narratives of urban identity.

\section{Findings from the case of the Southport Heritage Walk: Discursive aims and disruptive materialities}

Southport is an obvious choice for the site of a heritage walk for a number of reasons. It was one of European colonisers' earliest settlements on the Gold Coast, with first official land sales occurring in 1875 (Gold Coast City Council, 2009; Longhurst, 1994). In particular, Southport's growth at that time was supported by its increasing popularity as a seaside resort destination for visitors from the nearby city of Brisbane (Gold Coast City Council, 2009; Prideaux, 2004; Longhurst, 1994). This function was enabled by a 
railway connection operating from 1889 until its decommissioning in 1964, as well as by improved road networks and higher rates of automobile ownership (Prideaux, 2004; Longhurst, 1995, 1994). Simultaneously, Southport also established itself as a key commercial and administrative hub, being home to the local council's chambers, a variety of shops, and educational, health, financial and legal services (Gold Coast City Council, 2009; Longhurst, 1995). Despite a post-WW2 development boom and rapidly expanding population on the Gold Coast, Southport managed to retain more of its prewar built heritage than other areas of the city (Gold Coast City Council, 2010; Longhurst, 1994). This included significant Art Deco buildings the Hotel Cecil and the old Council Chambers, both of which are included in the SHW.

By the 1970s, Southport was neither the primary tourism destination nor the main service centre on the Gold Coast, having been eclipsed by Surfers Paradise and adjacent beachside suburbs (Gold Coast City Council, 2010). In recent years, there have been attempts to restore Southport 'as a dynamic and vibrant urban centre that will position the Gold Coast as a globally competitive business, investment and lifestyle destination' (Council of the City of Gold Coast, n.d.). This has included a rebranding of Southport as the Gold Coast's CBD, despite the facts that the city has long had dispersed, multiple 'centres' and that 'business' has predominantly focused on tourism and leisure-related industries. To bolster plans for revitalisation, in 2013 Southport was designated as a 'Priority Development Area', a status which 'removes development barriers, boosts investment opportunities and facilitates economic development' (Council of the City of Gold Coast, n.d.). Subsequent changes in the area have included a number of new high-rise developments, the implementation of a light rail rapid transit system, the renovation of a local shopping mall (Australia Fair), the establishment of a Chinatown, and the construction of a major aquatic centre for the 2018 Commonwealth 
Games. How practices of heritage unfold on the Gold Coast must therefore be understood in relation to this history of development. Recent construction, for instance, has eroded some older built heritage in the area, as well some earlier initiatives aimed at revitalisation, including the SHW.

\section{Whose heritage?}

The SHW, opened in 2009, was one of the earlier initiatives of revitalisation in Southport. Based in an area of the suburb identified by the Queensland State Government as being in need of renewal, the walk maps out a loop of the so-called CBD, with two optional extensions - one westwards to Owen Park (a sports field featuring a number of relocated heritage buildings), and the other eastwards to the Broadwater Parklands (a green space running parallel to an extensive estuary).

In any study of a heritage walk, it is important to consider which histories are being represented and for what purposes, and how these decisions were made. Stops along the walk serve to recognise built heritage or other physical spaces, including the former town hall, schools, hotels, theatres, churches, a bathing pavilion, a pier, and a cemetery. A digital brochure and three totem poles in situ elucidate some of the intangible aspects of this heritage, featuring memories from residents, details about when these spaces were established and how they were used, and sepia-toned photographs of the sites from when they were established or still in existence. Respondent 3 noted that decisions about what content to include were largely determined by the stories received through an oral histories project $-\mathrm{a}$ 'call for stories' pamphlet was distributed among groups such as local historical societies and submissions were received predominantly from older adults who had lived on the Gold Coast for many years. Content was also shaped by geography - which sites of significance were present in the area designated for renewal (northern Southport) - as 
well as what archival material was available at the time through the Local Studies Library.

Since the SHW was supposedly designed with community renewal in mind, it is essential to question the political dimensions of this construction (see Waterton \& Smith, 2010): that is, who is being framed as the 'community' for which the walk is intended to resonate? Whose heritage is being represented? What kind of story is being told? The SHW does not present a linear narrative, but stops are broadly related to Southport's function as a service centre and an early seaside tourism destination, and they tend to document mundane life - the site of a former butchery, railway station, corner shop, and a jewellery store. The walk focuses predominantly on European heritage from the mid-1870s to the mid-1950s. Only fleeting references are made to the activities of Indigenous Australians in this area prior to European colonisation (e.g. stop 23 ), with the brochure indicating that such histories can instead be explored at the Yugambeh Museum. Histories of the recent past are also noticeably absent, despite the fact that the area has changed substantially over the last few decades, not only in terms of its materiality, but also its demographics: over 40 per cent of residents in Southport North were born overseas, and of these residents approximately 37 per cent had arrived in Australia in the previous five years (well above the national averages of 29 per cent and 21.5 per cent respectively) (Australian Bureau of Statistics 2016 cited in .id n.d.). The SHW therefore reinforces conventional Western understandings of heritage which emphasise the value of material things, 'age, monumentality and/or aesthetics' (Smith, 2006, p. 3), as well as the mundane lives of local (mostly white, European) 'pioneers' of a certain area. Through the heritagisation process, these stories, sites and objects are assigned cultural significance and deemed worthy of preservation and transmission to "future generations for their "education", and to forge a sense of 
common identity based on the past' (Smith, 2006, p. 29). This is typical of governmentgenerated heritage walks, which Barber (2018) observes 'celebrate recognized heritage values' (p. 9) and 'emphasize[] dominant historical narratives that contribute to official histories' (p. 6).

As Kenworthy Teather and Chow $(2003$, p. 94) point out, there is a tendency for these selective narratives to 'incorporat[e] only those elements from the past that contribute to the image that is seen as desirable today'. On the Gold Coast, the implementation of a heritage walk in Southport contributes to the area's rebranding as a $\mathrm{CBD}$, furthering the city's discursive place-making project of reorienting its image to appear more like a sophisticated, conventional metropolis. Hence, the SHW is constructed through a heritage discourse that has particular political motivations and consequences that shape the present and future. As will be explored in the following subsection, however, the discourses and intentions underpinning the walk's creation (e.g. as related to community renewal, place-making and 'desirable' city branding) do not necessarily determine how heritage is received, interpreted and interacted with.

\section{Markers of a disappearing heritage}

Artefacts and information on a heritage walk are contextualised by the environment in which they are situated (Barber, 2018), and the walk is as much about engaging with the past as it is about experiencing the contemporary life of a place. Thus, beyond the discursive and representational constructions of the heritage walk, it is also crucial to consider how it is experienced in the context of lived spatiality (see also Soja, 1996). In the case of the SHW, the author's experience was shaped significantly by the observable changes Southport has undergone over recent years.

While the trail began as expected - at a totem pole featuring old photographs, historical information and excerpts from oral histories - problems began to arise almost 
immediately. After several minutes wandering around the street in confusion, it became apparent that the first three stops had no interpretative markers in the footpath, nor did the names in the brochure correspond to any of the shops that currently stand in their place. This was typical of the rest of the route - of the 17 numbered stops on the CBD loop, only three still had interpretive markers. In some places, they had been removed and paved over completely - a result of developments such as the light rail system in 2014 - while in other locations, small craters in the footpath indicated a marker that had since disappeared. At the same time, some markers had no corresponding number on the map, while others were faded or otherwise damaged. Although some stops still featured original buildings (e.g. stop 4, The Cecil Hotel; stop 7, the former Southport Town Hall), many others referred to structures which were demolished (e.g. stop 13, the former Southport Railway Station [1884-1964], is now a main road; stop 15, Chelmsford Guest House [1908-1961], is now a high-rise residential building).

The walk concluded in a way that was emblematic of the issues outlined here: the final two stops - stop 16, Balcultha (Southport's 'first house', est. 1877), and stop 17, the former Star of the Sea Convent (est. 1898) - had no interpretive markers, and there was nothing to be seen but an empty lot lined by construction fences (see Figure 3). Located on prime real estate adjacent to the Broadwater Parklands, these sites were demolished in 2016 to make way for a multi-tower high-rise development (Potts, 2016). The markers were removed when footpaths in the area were being repaved in preparation for the 2018 Commonwealth Games.

[Insert Figure 3 here] 
It is clear, then, that the actual lived experience of doing the heritage walk can diverge considerably from the expectations established through the brochure. Each stop is not numbered as one would expect, nor are the chosen sites of historical significance easy to identify, necessitating continuous use of the brochure and Google Maps for guidance. Hayes and MacLeod (2007, p. 54) warn trail developers against such possibilities for 'a mismatch between expectations created with literature and the reality of the experience on the ground'. On the SHW, the overall effectiveness of the walk is compromised in that the walker may expend considerable time and energy attempting to correctly navigate the walk rather than engaging with the everyday rhythms of Southport.

The SHW also reveals the extent to which development is at odds with preservation in Southport. In the first instance, the SHW draws one's attention to the disappearance of sites that, by virtue of their inclusion on the walk, have been designated as apparently valuable and meaningful. This reflects broader patterns within Southport and the Gold Coast at large. For example, an urban heritage report prepared in 2010 for the Gold Coast's city council identified a large number of architecturally significant homes that had been destroyed. Drawing on a photographic survey of the area from 1994, the report found that of the 62 homes in Southport that originated from the late nineteenth and early twentieth century, over half had been demolished by the time the report was written (see Gold Coast City Council, 2010, pp. 70-72). Many more have been torn down in the years thereafter.

In the second instance, the missing and damaged markers on the heritage walk itself highlights its precarious existence in the face of urban development. If the built heritage is largely not preserved, it is perhaps unsurprising that the interpretive markers implemented to commemorate that heritage are also not protected. Interviewees 
indicated that there were currently no plans for the SHW to be repaired or updated. Indeed, Respondent 1 indicated that the SHW has now been 'superseded' by a new initiative: the Gold Coast Commonwealth Walkway. Not listed among the city's heritage walks on its website, the Commonwealth Walkway is a 'unique entity' (Respondent 2) designed by the Outdoor Trust (UK) in partnership with the Council of the City of Gold Coast and launched in 2017 as a legacy project for the 2018 Commonwealth Games. The walkway features 37 large bronze plaques at sites of historical and scenic significance along a 10-kilometre route, stretching from Southport through to the tourist hub of Surfers Paradise, and is accompanied by a map, informational guide and activity booklet. The route of the Commonwealth Walkway intersects directly with that of the SHW at several points, including at the Southport Chambers building (see Figure 4) and along the Broadwater Parklands extension, but neither trail connects to the other. As is typical of the Gold Coast, rather than preserving or updating what already exists, the 'old' has been readily replaced by something newer and more appealing.

[Insert Figure 4 here]

Inadvertently, the SHW's role in place-making thus functions quite differently to what was intended. Rather than imbuing the urban landscape with a rich sense of heritage in a conventional sense, the walk re-asserts the ephemerality, impermanence and rapid change for which the Gold Coast is famous. Moreover, the walk reflects longstanding tensions in the city between considerations of community, culture and heritage and the demands of capitalism, development and tourism. In these ways, the walk does express particular facets of the city's identity and history - ones that resonate 
with the author as a local - albeit not those that are explicitly articulated by the material designed to support the walk itself. By extension, then, the walk also may express a sense of continuity, if that continuity is understood as the city's ongoing inclination towards transformation - driven by tourism and economic revitalisation - rather than stasis.

This case study of the SHW highlights how heritage is marked by contested meanings. As Barber (2018) notes, although government-generated heritage trails tend to present static, officially authorised versions of history, how they are encountered, on a micro-level by individual walkers, varies. The act of walking necessitates dynamic, embodied engagements, exploration and multiple interpretations (MacLeod, 2017; Dobson, 2011). Individuals can diverge from the trail and question its narratives and contents (Barber, 2018; MacLeod, 2017), and their interpretations are contingent on their own memories, histories, perspectives and affects. The author's interpretation of the SHW, for instance, is shaped by her understandings of the city's history and identity, informed by her experiences as a local and knowledge as a researcher. As the case study of the SHW demonstrates, people who undertake heritage walks do not passively consume the dominant narratives put forward. Rather, the walker actively negotiates and co-creates meanings of both heritage and place. Heritage is, thus, continually reconfigured in the present moment (Smith, 2006), and in the case of the SHW, its dominant historical narratives may be overshadowed by the walkers' encounters with the contemporary materiality of the space in which it is located.

\section{Conclusions and potentials}

The case study of the Gold Coast's SHW reveals some of the interconnections between the discursive, material and political elements that constitute urban heritage walks. The analysis in this article has elucidated how heritage unfolds in a rapidly changing city; 
how representations of history and narratives of urban identity are transmitted through the SHW's interpretive tools; and how the materialities of lived space disrupt these discourses. As strategies for place-making and urban renewal, heritage walks reveal the stories that a city wants to tell about itself in the present and into the future. In the case of the Southport Heritage Walk, this initiative marks an attempt to reorient the Gold Coast's image, to position Southport as the sophisticated CBD of a vibrant, world-class city that has a rich culture and history. The dominant narratives put forward in the SHW assign significance to built heritage of a certain era and to the mundane lives of Southport's early (predominantly European) 'pioneers'. These discourses are, however, enacted and engaged with in the broader context of the urban environment and its lived spatiality. Encounters with the SHW can therefore also highlight aspects of urban identity that diverge from what its creators intended to convey - through the readily observable damage and destruction of the walk's interpretive markers and the sites they seek to commemorate, as well as the presence of the new Commonwealth Walkway, the SHW is more emblematic of the Gold Coast's rapid evolution and ephemerality than its rich history and heritage. Thus, the SHW reveals the disjunctures that exist between preservation and development within the city.

While these pitfalls point to larger issues surrounding heritage policies in growing contemporary cities, they also highlight some of the practical steps that can be taken to make heritage walks more effective and engaging. At the most fundamental level, such initiatives need ongoing maintenance to ensure a degree of cohesion between interpretive tools (e.g. maps) and lived space. If tangible interpretive tools are unsustainable due to rapid development, alternative methods can be used - for example, adding a more dynamic digital component (e.g. an app or podcast). If such improvements are undertaken, the existing heritage walks may present themselves as 
more appealing attractions that can bolster the development of heritage tourism on the Gold Coast.

The design of heritage walks can also benefit from taking an approach that acknowledges multiple layers of history, incorporating aspects of the past that fall beyond the eras, stories and aesthetics conventionally enshrined in heritage initiatives. For example, on the Gold Coast, as well as representing more diverse Indigenous histories, there is also scope for including more 'heritage of the recent past' (Weaver, 2011). In an area like Southport that is experiencing not only rapid changes to the landscape, but also an increasingly diverse residential population of recent migrants, there is clearly a strong basis for the heritagisation of post-World War II sites, artefacts, events and practices, which are not necessarily part of living memory for many residents. Indeed, these material and demographic shifts themselves warrant recognition in heritage products, since they are playing a significant role in shaping the character of the region. As suggested by Markwell et al. (2004, pp. 465-466), 'rather than shy away from potentially controversial or problematic issues', the Gold Coast could usefully embrace its history of rapid change in telling the story of its identity. Effective heritage walks must thus be attentive to the actual materialities of the spaces in which they unfold, and recognise that consumers will be active, engaged participants in constructing, negotiating and contesting meaning. 


\section{Acknowledgements}

I would like to thank Elspeth Lee for her valuable research assistance during this project, Professor Sarah Baker and Associate Professor Patricia Wise for their feedback on an early draft of this article, and the two anonymous referees for their constructive feedback.

\section{References}

Al-hagla, K. S. (2010). Sustainable urban development in historical areas using the tourist trail approach: A case study of the Cultural Heritage and Urban Development (CHUD) Project in Saida, Lebanon. Cities, 27(4), 234-248.

Angrosino, M. (2007). Doing ethnographic and observational research. London: SAGE Publications.

Ashworth, G. J., \& Graham, B. (2005). Senses of place, senses of time and heritage. In G. J. Ashworth, \& B. Graham (Eds.), Senses of place: Senses of time (pp. 3-12). Farnham: Ashgate.

Barber, L. B. (2018). Heritage tours and trails on foot in Hong Kong: Towards a typology that crosses the tourist-local divide. Journal of Heritage Tourism. Advance online publication. doi:10.1080/1743873X.2018.1510937

Cantillon, Z. (2019). Resort spatiality: Reimagining sites of mass tourism. London: Routledge.

Chang, H. (2008). Autoethnography as method. Walnut Creek: Left Coast Press.

Council of the City of Gold Coast. (n.d.). Gold Coast CBD. Retrieved 5 December 2018 from http://www.goldcoast.qld.gov.au/business/southport-cbd-16933.html

City of Gold Coast. (2014). Culture Strategy 2023. Retrieved from http://www.goldcoast.qld.gov.au/documents/bf/cultural-strategy.pdf

Council of the City of Gold Coast. (2018). City Plan Version 6. Retrieved 15 October 2018 from https://cityplan.goldcoast.qld.gov.au/Pages/Plan/Book.aspx?exhibit=GCCC_Cit yPlan

Dobson, S. (2011). Sustaining place through community walking initiatives. Journal of Cultural Heritage Management and Sustainable Development, 1(2), 109-121.

Fagence, M. (2017). A heritage 'trailscape': Tracking the exploits of historical figures an Australian case study. Journal of Heritage Tourism, 12(5), 452-462. 
Feagin, J. R., Orum, A. M., \& Sjoberg, G. (Eds.). (1991). A case for the case study. Chapel Hill: University of North Carolina Press.

Flick, U. (2009). An introduction to qualitative research. 4th edn. London: SAGE Publications.

Friedmann, J. (2010). Place and place-making in cities: A global perspective. Planning Theory \& Practice, 11(2), 149-165.

Gray, A. (2003). Research practice for cultural studies: Ethnographic methods and lived cultures. London: SAGE Publications.

Haraway, D. (1988). Situated knowledges: The science question in feminism and the privilege of partial perspective. Feminist Studies, 14(3), 575-599.

Hayes, D., \& MacLeod, N. (2007). Packaging places: Designing heritage trails using an experience economy perspective to maximize visitor engagement. Journal of Vacation Marketing, 13(1), 45-58.

Hayes, D., \& MacLeod, N. (2008). Putting down routes: An examination of local government cultural policy shaping the development of heritage trails. Managing Leisure, 13(2), 57-73.

id. (n.d.). Southport - north: Birthplace. Gold Coast City community profile. Retrieved 1 December 2018 from https://profile.id.com.au/goldcoast/birthplace? WebID $=510$

Gold Coast City Council. (2009). A discovery guide to the Southport Heritage Walk. Retrieved from http://www.goldcoast.qld.gov.au/documents/bf/southportheritage-walk.pdf

Gold Coast City Council. (2010). Southport urban heritage and character strategy review. Retrieved from http://www.goldcoast.qld.gov.au/documents/ps/southport-urban-heritagecharacter-strategy-review.pdf

Kenworthy Teather, E., \& Chow, C. S. (2003). Identity and place: The testament of designated heritage in Hong Kong. International Journal of Heritage Studies, 9(2), 93-115.

Lefebvre, H. (1991 [1974]). The production of space. trans. D. Nicholson-Smith. Oxford: Blackwell Publishers.

Longhurst, R. (1994). Southport: Images of yesteryear 1880-1955. Gold Coast: Gold Coast City Council. 
Longhurst, R. (1995). Gold Coast: Our heritage in focus. South Brisbane: State Library of Queensland Foundation.

MacLeod, N. (2017). The role of trails in the creation of tourist space. Journal of Heritage Tourism, 12(5), 423-430.

Markwell, K., Stevenson, D., \& Rowe, D. (2004). Footsteps and memories: Interpreting an Australian urban landscape through thematic walking tours. International Journal of Heritage Studies, 10(5), 457-473.

Massey, D. (2005). For space. London: SAGE Publications.

Miles, S. (2017). Remembrance trails of the Great War on the Western Front: Routes of heritage and memory. Journal of Heritage Tourism, 12(5), 441-451.

Mullins, P. (1992). Cities for pleasure: The emergence of tourism urbanization in Australia. Built Environment, 18(3), 187-198.

Pierce, J., Martin, D. G., \& Murphy, J. T. (2010). Relational place-making: The networked politics of place. Transactions of the Institute of British Geographers, $36(1), 54-70$.

Potts, A. (2016, 3 September). Demolition work has begun on Southport's historic Star of the Sea Convent on Marine Parade. Gold Coast Bulletin. Retrieved from https://www.goldcoastbulletin.com.au/lifestyle/gold-coast-130/demolition-workhas-begun-on-southports-historic-star-of-the-sea-convent-on-marineparade/news-story/06aa26f8892aba63cf766bdcb3233140

Prideaux, B. (2002). Creating rural heritage visitor attractions: The Queensland Heritage Trails Project. International Journal of Tourism Research, 4, 313-323.

Prideaux, B. (2004). The resort development spectrum: The case of The Gold Coast, Australia. Tourism Geographies, 6(1), 26-58.

Queensland Government. (2008). Department of Housing: Annual report 2007-08. Retrieved from http://www.hpw.qld.gov.au/SiteCollectionDocuments/DoHAnnualReport2008.p df

Saiyed, A. A., Basalingappa, A., \& Sinha, P. K. (2017). Value network in heritage walks: Case studies of Ahmedabad City Walks. Journal of Heritage Management, 1(2), 191-204.

Silverman, D. (2013). Doing qualitative research. 4th edn. London: SAGE Publications. 
Sesma, E. (2015). 'A web of community': Uncovering African American historic sites in Deerfield, MA. Journal of Community Archaeology \& Heritage, 2(2), 121136.

Smith, A. (2018, 13 April). How the Gold Coast Games transformed a resort region into a city. The Conversation. Retrieved from https://theconversation.com/how-thegold-coast-games-transformed-a-resort-region-into-a-city-94877

Smith, L. (2006). Uses of heritage. Routledge: London.

Soja, E. W. (1996). Thirdspace: Journeys to Los Angeles and Other Real-and-Imagined Places. Oxford: Blackwell Publishers.

State of Queensland. (2009). Historical Tables, Population, 1823 to 2008, (Q150 Release). Retrieved from http://www.qgso.qld.gov.au/products/tables/historical-tablesdemography/historical-tables-demography.xls

Stephens, K. (2013, 12 July). Gold Coast plans oasis for 'cultural wasteland'. Brisbane Times. Retrieved from https://www.brisbanetimes.com.au/national/queensland/gold-coast-plans-oasisfor-cultural-wasteland-20130712-2pv6b.html

Taylor, E. P. (2015). Alternate routes: Interpretive trails, resistance, and the view from East Jerusalem. Journal of Community Archaeology \& Heritage, 2(2), 106-120.

Timothy, D. J., \& Boyd, S. W. (2015). Tourism and trails: Cultural, ecological and management issues. Bristol: Channel View Publications.

Tourism and Events Queensland. (2018). Gold Coast regional snapshot: Year ending December 2017. Retrieved 16 October 2018 from https://cdn2teq.queensland.com/ /media/35c1e27252c54a93a64f78769c156f2e.ashx?vs=1\& $\mathrm{d}=20180424 \mathrm{~T} 110010$

Waterton, E., \& Smith, L. (2010). The recognition and misrecognition of community heritage. International Journal of Heritage Studies, 16(1-2), 4-15.

Weaver, D. B. (2011). Contemporary tourism heritage as heritage tourism: Evidence from Las Vegas and Gold Coast. Annals of Tourism Research, 38(1), 249-267.

Winter, T. (2013). Clarifying the critical in critical heritage studies. International Journal of Heritage Studies, 19(6), 532-545.

Wise, P. (2006). Australia's Gold Coast: A city producing itself. In C. Lindner (Ed.), Urban space and cityscapes: Perspectives from modern and contemporary culture (pp. 177-191). New York: Routledge. 



\section{Figure captions}

Figure 1. On the Southport Heritage Walk, interpretive markers include historical information, photographs and/or directions.

Figure 2. Totem pole on the Southport Heritage Walk.

Figure 3. The former site of the Star of the Sea Convent.

Figure 4. An informational panel for the Commonwealth Walkway, located close to one of the Southport Heritage Walk's totem poles (see top left). 